\title{
Original
}

\section{The Role of the Wnt Signaling Pathway in the Osteogenic Differentiation of Human Adipose-derived Stem Cells under Mechanical Stimulation}

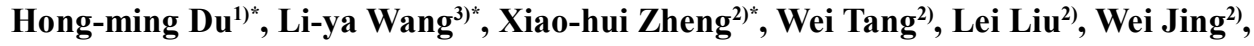 \\ Yun-feng Lin'), Wei-dong Tian ${ }^{2)}$ and Jie Long ${ }^{1,2)}$ \\ 1) The State Key Laboratory of Oral Diseases, Sichuan University, Chengdu China \\ 2) Department of Oral and Maxillofacial Surgery, West China College of Stomatology, Sichuan University, Chengdu China \\ 3) Department of Stomatology, The First Affiliated Hospital of Soochow University, Suzhou China \\ (Accepted for publication, February 13,2015)
}

\begin{abstract}
This study investigates the effects of the Wnt signaling pathway on the osteogenic differentiation of human adipose-derived stem cells (hASCs) under tensile stress. hASCs cultured in vitro were divided into 4 groups: Group A, hASCs; Group B, Wnt5a RNAi-treated hASCs; Group C, hASCs under tensile stress; and Group D, Wnt5a RNAi-treated hASCs under tensile stress. Five days after treatment, the genes associated with the $\mathrm{Wnt} / \beta$-catenin and $\mathrm{Wnt} / \mathrm{Ca}^{2+}$ pathways were analyzed in all groups by real-time RT-PCR; the Wnt10b, Wnt5a, RUNX2 and SPP1 proteins were analyzed by western blot analysis. Compared with the expression in Groups A and B, all the genes and proteins in Groups C and D had higher expression, except for Wnt5a in Group D. Compared with Group C, Wnt5a, RhoA,RUNX2 and ALPL had lower expression in Group D, but the markers associated with $\mathrm{Wnt} / \beta$-catenin had higher expression. The results suggest that tensile stress can promote maturation and osteogenic differentiation in hASCs and also activate the $\mathrm{Wnt} / \beta$-catenin and $\mathrm{Wnt} / \mathrm{Ca}^{2+}$ pathways. The $\mathrm{Wnt} / \mathrm{Ca}^{2+}$ pathway may have the potential to inhibit the $\mathrm{Wnt} / \beta$-catenin pathway. Wnt5a knock down seemed to increase the expression of the $\mathrm{Wnt} / \beta$-catenin pathway, which is activated by Wnt $10 \mathrm{~b}$.
\end{abstract}

Key words: Human adipose-derived stem cell, Tensile stress, Osteogenic differentiation, Wnt signaling pathway

\section{Introduction}

Previous research has shown that cells and tissues in their native environments are subjected to various forms of mechanical loading, such as compression, tension, and shear stress. These mechanical forces play important roles in the regulation of in vivo cellular functions, including gene induction, protein synthesis, cell growth, and differentiation, all of which are essential to maintain or alter tissue homeostasis. Previously, scholars have extensively studied a variety of cells ${ }^{1-3)}$, particularly mesenchymal stem cells (MSCs) and the effect of mechanical stimulation on their differentiation ${ }^{4-6}$. Some studies have indicated that tensile stress can promote an osteogenic response in human adiposederived stem cells (hASCs), a type of MSCs ${ }^{7-9)}$.

The advantages of using adipose-derived stem cells (ASCs) are obvious, including their abundance and accessibility as a cell source and their ease of expansion in culture. Furthermore, animal experiments have shown that the osteogenic differentiation ability

\footnotetext{
* These three authors contributed equally to this work. Correspondence to: Dr. Jie Long, Department of Oral and Maxillofacial Surgery, West China College of Stomatology, Sichuan University, Chengdu 610041, PR China; Tel: +86 28 85503406; Fax: +86 28 85501456; E-mail: dr.jielong@hotmail.com
}

of murine ASCs does not significantly decrease with age ${ }^{10)}$. Recently, many studies have demonstrated that hASCs represent an important new cell source for bone tissue engineering ${ }^{11-13)}$.

The process of osteogenic differentiation of hASCs under tensile stress is regulated by a series of factors, including cytokines, signaling molecules and surrounding environmental factors ${ }^{14,15}$. Wnt signaling plays a key role in osteogenic differentiation ${ }^{16-19}$. The Wnt signaling pathway mainly consists of three branches: the Wnt/ $\beta$-catenin pathway (the canonical Wnt signaling pathway), the Wnt/PCP pathway (the planner cell polarity pathway) and the $\mathrm{Wnt} / \mathrm{Ca}^{2+}$ pathway ${ }^{20-23)}$. Some studies have confirmed that genes of the $\mathrm{Wnt} / \beta$-catenin and $\mathrm{Wnt} / \mathrm{Ca}^{2+}$ pathways have significantly different expression patterns during the osteogenic differentiation of stem cells induced by mechanical and chemical stimuli, suggesting they play distinct roles in development and osteogenic differentiation ${ }^{16,19)}$. High expression of Wnt10b, one of the important $\mathrm{Wnt} / \beta$-catenin-activating molecules, can promote osteogenesis $^{24-27)}$. The non-canonical Wnt5a, an important Wnt/ $\mathrm{Ca}^{2+}$ pathway-activating molecule, can cause the Ror2 extracellular domain to fuse with the LPR6 intracellular domain in vitro, activating the $\mathrm{Wnt} / \mathrm{Ca}^{2+}$ pathway through a series of complex 


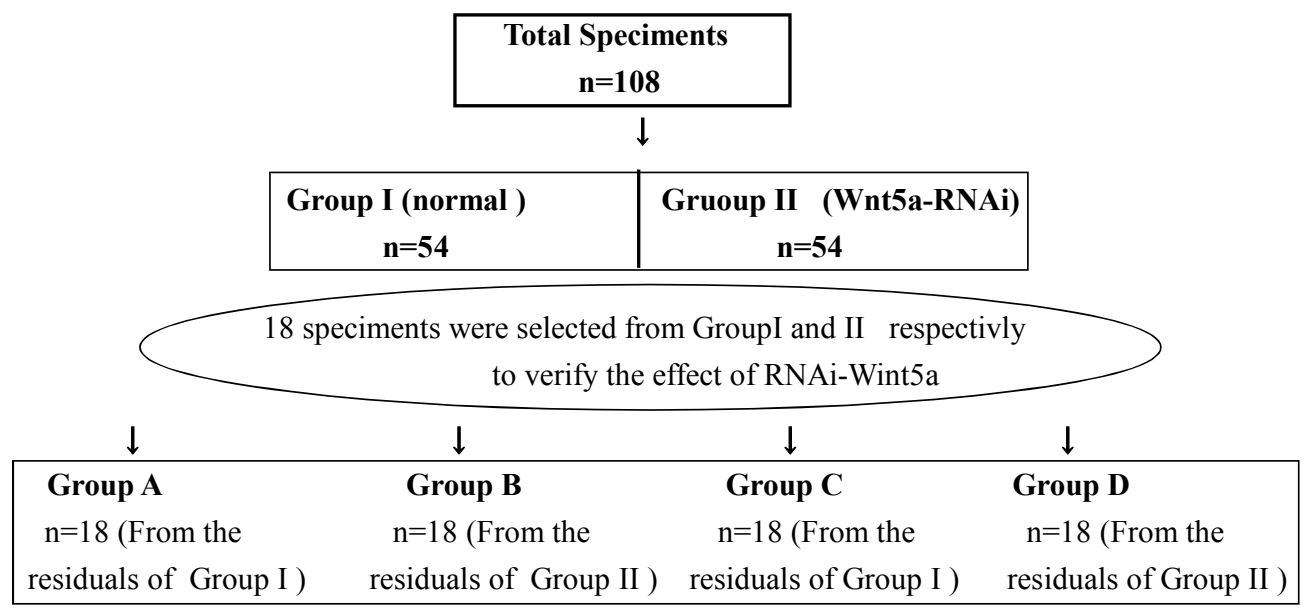

Figure 1. Classification tree showing the group treatment scheme of 108 specimens in experiments 1 and 2 according to the experimental design.

processes $^{28-31)}$. Recently, a study demonstrated that Wnt5a and its downstream molecule RhoA can act on the RUNX2 gene and increase its expression to promote osteogenic differentiation ${ }^{32}$. These results indicate that the roles of the $\mathrm{Wnt} / \mathrm{Ca}^{2+}$ and $\mathrm{Wnt} / \beta$ catenin pathways in the osteogenic differentiation of MSCs are closely related. However, the results of similar studies remain controversial ${ }^{33-35)}$, and the effect of Wnt signaling on the osteogenic response of hASCs under mechanical stimulation remains unclear. In this study, we investigated the effect of Wnt signaling on the osteogenic differentiation of hASCs under tensile stress in vitro using a four-point bending apparatus. This work focused on the effects of tensile stress on the gene and protein expression of $\mathrm{Wnt}$ signaling components and the relationship between the $\mathrm{Wnt} / \beta$ catenin pathway, which is activated by Wnt $10 \mathrm{~b}$, and the $\mathrm{Wnt} / \mathrm{Ca}^{2+}$ pathway, which is activated by Wnt5a.

\section{Materials and Methods}

\section{Experimental Design}

In this study, we obtained human adipose tissue from patients who received skin flap graft transplantations. The enzymedigestion method was used to isolate hASCs from the human adipose tissue. The grouping is illustrated in Fig 1 in detail. A total of $108 \mathrm{hASCs}$ specimens were divided randomly into 2 groups of 54 specimens each: Group I hASCs were cultured normally and Group II hASCs were subjected to Wnt5a knock down by RNAi. To verify the Wnt5a knock down, 18 specimens from each group were examined by cellular immunofluorescence, real-time RT-PCR and western blots. The remaining hASCs were then assigned to 4 groups (A, B, C, D): Group A, unstimulated hASCs; Group B, Wnt5a RNAi-treated hASCs; Group C, hASCs under tensile stress; and Group D, Wnt5a RNAi-treated hASCs under tensile stress. The cells in groups A and C (18 specimens each) came from the residual specimens from Group I, and the cells in groups B and D (18 specimens each) came from the residual specimens in Group II. The cells from all groups were cultured in alpha-modified minimum essential medium ( $\alpha$-MEM) with 10 $\%$ fetal bovine serum (FBS). Tensile stress was applied using a four-point bending apparatus. Five days after the tensile stress, Group C and D cells were harvested; Group A and B cells were harvested at the same time point. All of the Wnt component and target genes (Wnt10b, Wnt5a,LRP5,LRP6, $\beta$-catenin, RhoA, RUNX2, ALPL, c-Fos,c-Jun, eNOS, COX2 and Cxn43) were analyzed by real-time RT-PCR. Wnt10b, Wnt5a, RUNX2 and SPP1 protein levels were analyzed by western blot. All of these independent experiments were repeated 3 times.

\section{Cell isolation and culture}

Six patients who had received skin flap grafting transposition operations at the West China Hospital of Stomatology of Sichuan University donated subcutaneous adipose tissue, three males and three females. Their ages ranged from 18 to 25 years. The ethics committee of the West China Hospital of Stomatology of Sichuan University approved this study, and informed consent was obtained from all subjects. The subcutaneous adipose tissues obtained from the patients were immersed in $\alpha$-MEM (Thermo Scientific HyClone, Logan, UT, USA) with $10 \%$ FBS (Thermo Scientific HyClone, Logan, UT, USA) and stored at $-4^{\circ} \mathrm{C}$. Subsequently, the subcutaneous adipose tissue was digested for 30 min with $0.075 \%$ collagenase type I (Sigma-Aldrich, St. Louis, MO, USA) at $37{ }^{\circ} \mathrm{C}$. The relatively dense cells released by digestion were separated from the adipocytes by centrifugation $(1200 \times \mathrm{g}, 10 \mathrm{~min})$ and resuspended in $160 \mathrm{mM}$ ammonium chloride to lyse the red blood cells. These resuspended cells were cultured in $\alpha$-MEM with $10 \%$ FBS and $100 \mathrm{U} / \mathrm{ml}$ penicillin/ streptomycin (Sigma-Aldrich, St. Louis, MO, USA) under the standard conditions of $37{ }^{\circ} \mathrm{C}, 5 \% \mathrm{CO}_{2}$, and $95 \%$ humidity. After 2 days, phosphate-buffered saline (PBS) was used to wash the cell monolayer, and fresh medium was then added to the plastic 
Hong-ming Du et al.: Wnt Signaling in the Osteogenic Differentiation of Human Adipose-derived Stem Cells under Mechanical Stimulation

Table 1. Primers used in real-time RT-PCR

\begin{tabular}{|c|c|c|c|}
\hline Symbol & Gene & Accession No & Primer sequence \\
\hline Wnt10B & $\begin{array}{l}\text { wingless-type MMTV } \\
\text { integration site family, } \\
\text { member } 10 \mathrm{~b}\end{array}$ & NM_003394 & $\begin{array}{l}\text { 5'-CATCCAGGCACGAATGCGA } \\
\text { 5'-CGGTTGTGGGTATCAATGAAGA }\end{array}$ \\
\hline Wnt5a & $\begin{array}{l}\text { wingless-type MMTV } \\
\text { integration site family, } \\
\text { member } 5 \mathrm{a}\end{array}$ & NM_003392 & $\begin{array}{l}\text { 5'-TGGCAGGACTTTCTCAAGGACA } \\
\text { 5'-TTGACGTCGTGACACCTATTGTG }\end{array}$ \\
\hline LRP5 & $\begin{array}{l}\text { low-density lipoprotein } \\
\text { receptor-related protein } 5\end{array}$ & NM_002335 & $\begin{array}{l}\text { 5'-ACTCGCTGTGAGGAGGACAAT } \\
\text { 5'-GGCAGGCGCATGTGTAGAA }\end{array}$ \\
\hline LRP6 & $\begin{array}{l}\text { low-density lipoprotein } \\
\text { receptor-related protein } 6\end{array}$ & NM_002336 & $\begin{array}{l}\text { 5'-TTTATGCAAACAGACGGGACTT } \\
\text { 5'-GCCTCCAACTACAATCGTAGC }\end{array}$ \\
\hline â-catenin & $\begin{array}{l}\text { catenin (cadherin-associated } \\
\text { protein), beta } 1\end{array}$ & NM_001904 & $\begin{array}{l}\text { 5'-TGGACTCTGGAATCCATTCTG } \\
\text { 5'-ACTCACCCTTGTCCCTAAAA }\end{array}$ \\
\hline RhoA & $\begin{array}{l}\text { ras homolog family member } \\
\text { A }\end{array}$ & NM_001664 & $\begin{array}{l}\text { 5'-CTGGTGATTGTTGGTGATGG } \\
\text { 5'-CCGTCCTTCTAATACTAGCG }\end{array}$ \\
\hline RUNX2 & $\begin{array}{l}\text { Runt-related transcription } \\
\quad \text { factor } 2\end{array}$ & NM_001024630 & $\begin{array}{l}\text { 5'-ACAGTAGATGGACCTCGGGAAC } \\
\text { 5'-AAACAAGAGACTGGCGGAGT }\end{array}$ \\
\hline ALPL & $\begin{array}{l}\text { Alkaline phosphatase, } \\
\text { liver/bone/kidney }\end{array}$ & NM_000478 & $\begin{array}{l}\text { 5'-CCTGGACCTCGTTGACACCT } \\
\text { 5'-AGAGAAGCTCGGTCCCCTG }\end{array}$ \\
\hline c-Fos & $\begin{array}{l}\text { FBJ murine osteosarcoma } \\
\text { viral oncogene homolog }\end{array}$ & NM_003394 & $\begin{array}{l}\text { 5'-CATCCAGGCACGAATGCGA } \\
\text { 5'-CGGTTGTGGGTATCAATGAAGA }\end{array}$ \\
\hline c-Jun & proto-oncogene c-Jun & NM_002228 & $\begin{array}{l}\text { 5'-TCCAAGTGCCGAAAAAGGAAG } \\
\text { 5'-CGAGTTCTGAGCTTTCAAGGT }\end{array}$ \\
\hline eNOS & $\begin{array}{l}\text { endothelial nitric-oxide } \\
\text { synthase }\end{array}$ & NM_000603 & $\begin{array}{l}\text { 5'-TGATGGCGAAGCGAGTGAAG } \\
\text { 5'-ACTCATCCATACACAGGACCC }\end{array}$ \\
\hline $\mathrm{COX} 2$ & cyclooxygenase-2 & NM_000963 & $\begin{array}{l}\text { 5'-CTGGCGCTCAGCCATACAG } \\
\text { 5'-CGCACTTATACTGGTCAAATCCC }\end{array}$ \\
\hline Cxn43 & connexin 43 & NM_000165 & $\begin{array}{l}\text { 5'-CAATCTCTCATGTGCGCTTCT } \\
\text { 5'-GGCAACCTTGAGTTCTTCCTCT }\end{array}$ \\
\hline GAPDH & $\begin{array}{l}\text { glyceraldehyde-3-phosphate } \\
\text { dehydrogenase }\end{array}$ & AF 106860 & $\begin{array}{l}\text { 5'-TGGGTGTGAACCACGAGAA } \\
\text { 5'-GGCATCGACTGTGGTCATGA }\end{array}$ \\
\hline
\end{tabular}

flasks (Corning, Corning, NY, USA). We then changed the culture medium every 2-4 days. The cells reached $80 \%$ confluence in 5 7 days and were then resuspended for subculturing. The multidifferentiation potential of these cells was demonstrated previously in our laboratory ${ }^{36}$. We used cells at passage 5 in all of the experiments in this study.

\section{Expression of RNAi-silenced Wnt5a in hASCs}

Group II cells were subjected to RNAi against Wnt5a. The cells were seeded in 6-well plates (Corning, Corning, NY, USA) in $\alpha$-MEM with FBS and treated with the siRNAs at 30-50\% confluence. One day prior to the siRNA transfection, the medium was changed to $\alpha$-MEM without FBS. The Wnt5a siRNA sequence was as follows: F: 5'-CCGGAUAACCUUGUAACAUAU-3' R: 5' - AUAUGUUACAAGGUUAUCCGG-3' (Biomics Biotechnology, Nantong, China). First, 20 pmol of siRNA was mixed with $50 \mu \mathrm{l}$ of $\alpha$-MEM medium. One microliter of Lipofectamine $^{\mathrm{TM}} 2000$ (Invitrogen, Carlsbad, CA, USA) was added to $50 \mu \mathrm{l}$ of $\alpha$-MEM medium and incubated at room temperature (RT) for 5 minutes; the siRNA- $\alpha$-MEM mixture was then added to this mixture and incubated at RT for 20 minutes. This Lipofectamine $^{\mathrm{TM}} 2000$-siRNA mixture was added to the Group II 
A

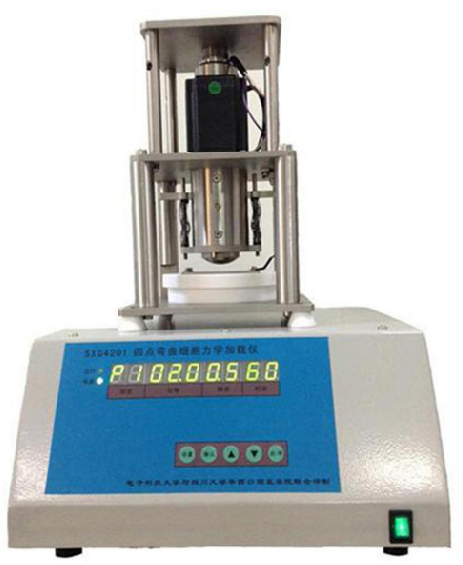

B

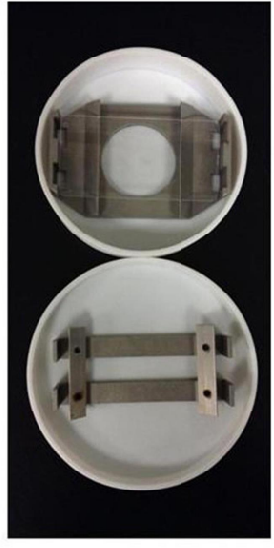

$\mathrm{C}$

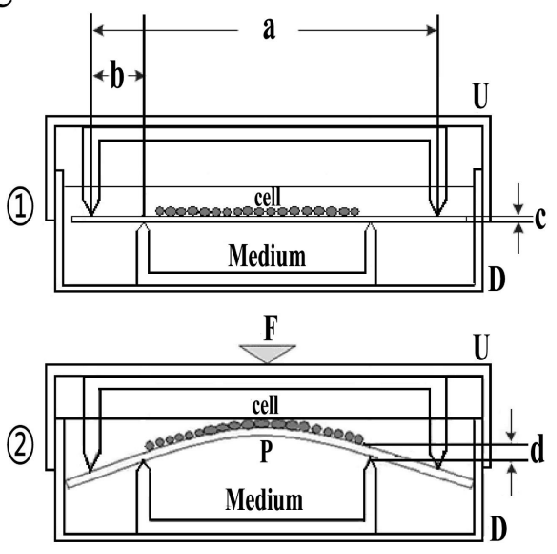

Figure 2. The four-point bending apparatus. (A) Computer controlled unit and the actuator unit. (B) Petri dish with a special cell culture plate. (C) Schematic of cyclic uniaxial tensile strain on the cultured cells. The culture plate is placed between the four supporting rods in the Petri dish and is submerged in $100 \mathrm{~mL}$ medium in the bottom of the Petri dish. The plate is bent by the punching head of the actuator unit, and the cells attached on its surface are exposed to uniaxial stretch strain. (F, punching head; P, cell cultured plates; U, Petri dish cover; D, Petri dish bottom.) The strain loaded onto the cells can be calculated using this formula: $a=c d / b(a-1.33 b)$, where å $=$ strain capacity, $a=$ the distance between the two support rods of the Petri dish cover, $b=$ the distance between the same side support rods of the Petri dish cover and bottom, $\mathrm{c}=$ the thickness of the cell culture plates, and $\mathrm{d}=$ vertical displacement.

cells, which were then incubated at $37{ }^{\circ} \mathrm{C}, 5 \% \mathrm{CO}_{2}$, and $95 \%$ humidity for 48 hours. After that the cells in Group I and II were harvested immediately, and 18 specimens of them were selected randomly for examinations to verify the effects of Wnt5a RNAi and the rest were seeded for further woks. The effect of the Wnt5a RNAi was verified using cellular immunofluorescence, real-time RT-PCR and western blots.

\section{Determination of Wnt5a Expression in hASCs treated with Wnt5a siRNA using Cellular Immunofluorescence, Real-Time RT-PCR and Western blot examination}

Six specimens from Groups I and II (Wnt5a RNAi) were randomly chosen for cellular immunofluorescence to detect the expression of the Wnt5a protein. The specimens from each group were washed three times with PBS for $5 \mathrm{~min}$ each. The specimens were fixed with $10 \%$ polyoxymethylene for $15 \mathrm{~min}$ and then washed three times with PBS for 5 min each. The specimens were covered with $0.2 \%$ Triton X-100 (Sigma-Aldrich, St. Louis, MO, USA) at RT for $30 \mathrm{~min}$ and then washed three times for $5 \mathrm{~min}$ each. The specimens were then covered with $1 \%$ BSA and incubated at $37^{\circ} \mathrm{C}$ for $30 \mathrm{~min}$. Wnt5a primary antibody (Abcam, Hong Kong, China) was diluted in PBS according to the manufacturer's instructions and was added to the specimens. The specimens were then incubated overnight at $4{ }^{\circ} \mathrm{C}$ and subsequently rewarmed at $37^{\circ} \mathrm{C}$ for 1 hour the following day. The specimens were washed three times for $5 \mathrm{~min}$ with PBS. The fluorescein isothiocyanate-labeled secondary antibody (goat anti-rabbit IgG, Zhongshan Biotechnology, Beijing, China) was diluted in PBS following the manufacturer's instructions and then added to the surface of the specimens. The specimens were then incubated in the dark at $37^{\circ} \mathrm{C}$ for $45 \mathrm{~min}$, washed three times for $5 \mathrm{~min}$ with PBS, and finally observed and photographed using an optical microscope (Nikon, Tokyo, Japan).

Six specimens from Groups I and II (Wnt5a-RNAi) were randomly chosen for real-time RT-PCR to detect the expression of the Wnt5a gene. The Wnt5a and glyceraldehyde-3-phosphate dehydrogenase (GAPDH) primers are listed in Table 1; they were synthesized by Invitrogen (Guangzhou, China). Total RNA was isolated using TRIzol (Invitrogen, Carlsbad, CA, USA) according to the manufacturer's instructions. The RNA concentrations and purity were determined using a spectrophotometer (Nano Vue; GE Healthcare Bio-Science, Piscataway, NJ, USA). Reverse transcription was carried out using a PrimeScript RT Reagent Kit with gDNA Eraser (TaKaRa, Dalian, China). The cDNA preparations were checked using spectrophotometry (i.e., A260/ A280 analysis). Real-time PCR was run on an ABI 7300 realtime PCR system (Applied Biosystems, Foster City, CA, USA) using the SYBR Premix Ex TaqII Kit (TaKaRa, Dalian, China) with the following program: initial activation of the Fast Start Taq polymerase at $95{ }^{\circ} \mathrm{C}$ for $30 \mathrm{sec}$, followed by approximately 40 cycles of $95{ }^{\circ} \mathrm{C}$ for $10 \mathrm{sec}$ and $60{ }^{\circ} \mathrm{C}$ for $31 \mathrm{sec}$. The threshold cycle values were determined automatically by the ABI 7300 realtime PCR system software (Applied Biosystems, Foster City, CA, USA). For each reaction, a melting curve was generated to test for primer dimer formation and false priming.

Six specimens from Groups I and II (Wnt5a-RNAi) were randomly chosen for Western blots to detect the expression of the Wnt5a protein. Briefly, the cells were washed with PBS twice, and total cellular protein was extracted using the Total Protein Extraction Kit (KeyGen, China) according to the manufacturer's 
Hong-ming Du et al: : Wnt Signaling in the Osteogenic Differentiation of Human Adipose-derived Stem Cells under Mechanical Stimulation instructions. Sample protein concentrations were detected using a BCA Kit (Beyotime, Jiangsu, China) according to the manufacturer's instructions. The protein samples were diluted approximately 1 to 4 using $5 \times$ SDS loading buffer, heated to 100 ${ }^{\circ} \mathrm{C}$ for 3 min and stored at $-20{ }^{\circ} \mathrm{C}$. Equal amounts of protein (20$40 \mu \mathrm{g}$ ) from each sample were loaded onto a 10\% SDS-PAGE gel for electrophoresis (Bio-Rad, Hercules, CA, USA). The separated proteins were then transferred to a PVDF membrane (Bio-Rad, Hercules, CA, USA). The membrane was blocked in 5\% non-fat milk in TBS-Tween 20 for 2 hours at $4^{\circ} \mathrm{C}$. The membrane was then incubated with Wnt5a or GAPDH primary antibodies (Abcam, Hong Kong, China) diluted in $5 \%$ non-fat milk/TBS-Tween 20 according to the manufacturer's instructions for 2 hours at $37^{\circ} \mathrm{C}$. The secondary antibody (goat anti-rabbit IgG; Zhongshan Biotechnology, China) was diluted in 5\% non-fat milk/TBS-Tween 20 and applied to the membrane for 2 hours at $37^{\circ} \mathrm{C}$. The membrane was washed 3 times with $0.01 \%$ TBS/Tween 20 for 5 min after the antibody incubation. Immunocomplexes were visualized using an enhanced chemiluminescence reagent (Millipore, Billerica, MA, USA) and photographed using the Quantity One software (Bio-Rad, Hercules, CA, USA).

\section{Cell seeding and application of mechanical stretching}

Mechanical stimulation of tensile stress was applied using a four-point bending apparatus (Fig. 2) designed by West China Medical University and the University of Electronic Science and Technology of China. The apparatus included an actuator containing a special resilient cell culture plate (Fig. 2B), which was driven by an electrical stepper motor and a computercontrolled unit (Fig. 2A). The special cell culture plate (length $\times$ width, $8.0 \times 3.0 \mathrm{~cm}$ ) was cut from the bottom of a plastic culture flask (Corning, Corning, NY, USA). The mechanism of this apparatus was previously described ${ }^{37}$. Our previous work confirmed that the tensile stress generated by the four-point bending apparatus was successfully transferred to cells.

According to the experimental design, untreated or Wnt5a siRNA-treated cells at passage 5 were seeded onto $150 \mathrm{~cm}^{2}$ plastic culture plates at a density of $1.5 \times 10^{5}$ cells/plate and cultured for 48 hours under standard conditions ( $\alpha$-MEM containing $10 \%$ FBS at $37{ }^{\circ} \mathrm{C}, 5 \% \mathrm{CO}_{2}$ and $95 \%$ humidity). The plastic cell culture plates were then placed in stretching dishes filled with $\alpha$ MEM plus $10 \% \mathrm{FBS}$ and subjected to cyclic uniaxial tensile stress $(0.5 \mathrm{~Hz}, 2000 \mu \varepsilon, 2 \mathrm{~h} / \mathrm{d})$. After daily mechanical loading for 5 days, the cell plates were put in plastic culture dishes for continued culture. Group A and B cells were also seeded at passage 5 on plastic cell culture flasks and cultured for 48 hours under standard conditions, and they remained in standard culture for the duration of the experiment. After 5 days of mechanical loading, the Group $\mathrm{C}$ and D cells were collected immediately; at the same time point, Group A and B cells were also collected for examination.

Analysis of Wnt- and Osteogenesis-associated Gene Expression and Cells under Tensile Stress using Real-Time RT-PCR

Cell samples from each group (A-D, 9 specimens each) were randomly chosen for real-time RT-PCR detection. The expression of genes associated with the Wnt signaling pathway and osteogenesis. (Wnt10b, Wnt5a, LRP5, LRP, $\beta$-catenin£ $\neg$ RhoA, RUNX2, ALPL, c-Fos, c-Jun, eNOS, COX2 and Cxn43; Table 1) was analyzed. Gene-specific primers were synthesized by Invitrogen (Guangzhou, China). The Real-Time RT-PCR procedure was performed as described above in the Materials and Methods section 2.4.

\section{Analysis of Wnt- and Osteogenesis-associated Protein Expression in Cells under Tensile Stress using Western blots}

Cell samples from each group (A-D, 9 specimens each) were randomly chosen for Western blot analysis. The expression of proteins associated with the Wnt signaling pathway and osteogenesis, such as Wnt10b, Wnt5a, RUNX2, and SPP1 (Abcam, Hong Kong, China), was analyzed. The Western blot procedure was performed as described above in the Materials and Methods section 2.4.

\section{Statistical Analysis}

The data acquired from this study were analyzed by one way and two way ANOVA using the SPSS 17.0 software package (SPSS, Chicago, IL, USA). $p<0.05$ was considered statistically significant.

\section{Results}

\section{Expression of Wnt5a in siRNA-treated hASCs}

The immunofluorescence results are shown in Fig. 3A. Compared with Group I, the fluorescence intensity of Wnt5a in Group II cells was significantly reduced. The results of real-time RT-PCR (Fig. 3B-a) and Western blot analysis (Fig. 3B-b) are shown in Fig. 3B; the relative quantitative analysis showed that Wnt5a expression was significantly lower in Group II than in Group I $(p<0.05)$.

\section{Analysis of Wnt- and Osteogenesis-associated Gene Expression in Cells under Tensile Stress using Real-Time RT-PCR}

In this study, the expression of genes associated with the Wnt signaling pathway (Wnt10b, Wnt5a, LRP5, LRP6, $\beta$-catenin, and RhoA) and Wnt target genes (RUNX2, ALPL ,c-Fos, c-Jun, eNOS, COX2 and Cxn43) was analyzed using real-time RT-PCR. The results of the real-time RT-PCR analyses are shown in Figure 4. Compared with Group, the expression of many genes (Wnt10b, LRP5, LRP6, $\beta$-catenin, c-Fos, c-Jun, eNOS, COX2 and Cxn43) was significantly higher in group $\mathrm{B}(p<0.05)$. Conversely, Wnt5a and RhoA expression levels were significantly lower $(p<0.05)$, and there was no significant difference in RUNX2 and 


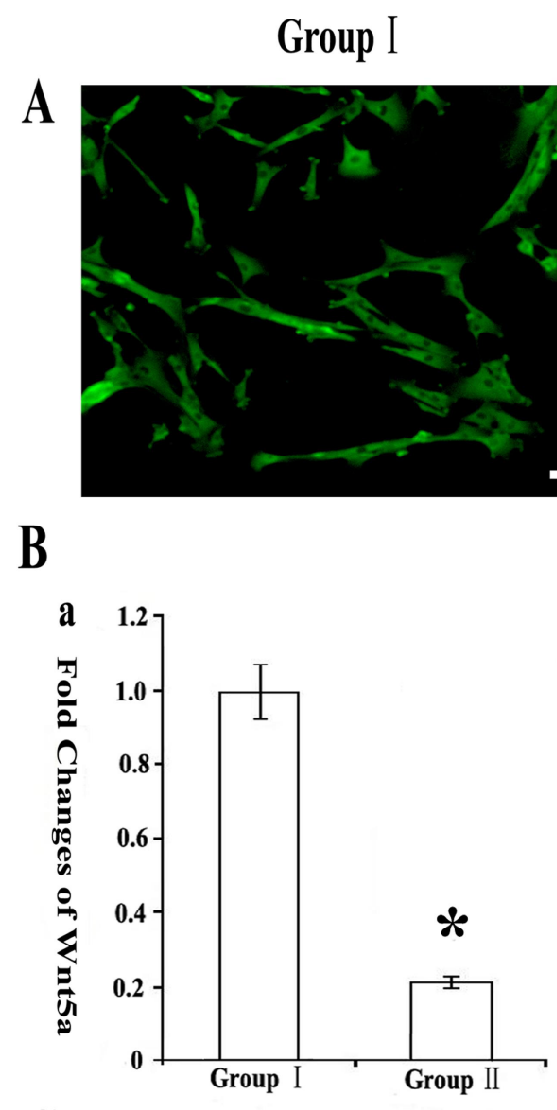

$\mathrm{C}$

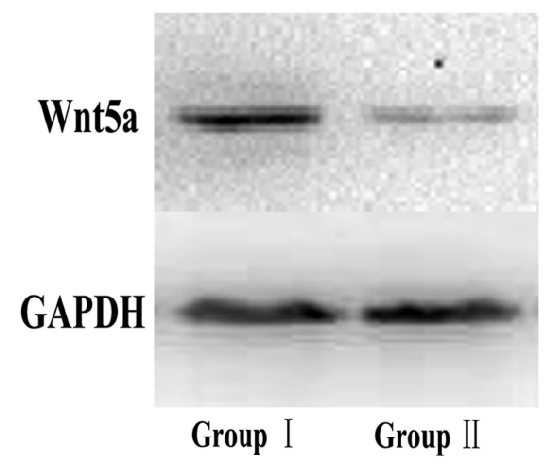

ALPL expression $(p<0.05)$. Compared with Groups A and B, the expression of all the genes analyzed was significantly higher in Groups C and D $(p<0.05)$, with the exception of Wnt5a in Group D. Compared with Group B£ $\neg$ Wnt5a expression was significantly higher in Group D $(\mathrm{p}<0.05)$. Compared with Group C, Wnt5a, RhoA, RUNX2 and ALPL expression levels were significantly lower in Group D $(p<0.05)$; however, the levels of Wnt10b, LRP5, LRP6, $\beta$-catenin, c-Fos, c-Jun, eNOS, COX2 and Cxn43 were significantly higher $(p<0.05)$. Two-way ANOVA test showed the tensile stress $(p<0.05)$, Wnt5a siRNA $(p<0.05)$, combination of tensile stress and Wnt5a siRNA $(p<0.05)$ affected the genes expression associated with osteogenic differentiation of human adipose-derived stem cells significantly.

\section{Group II}
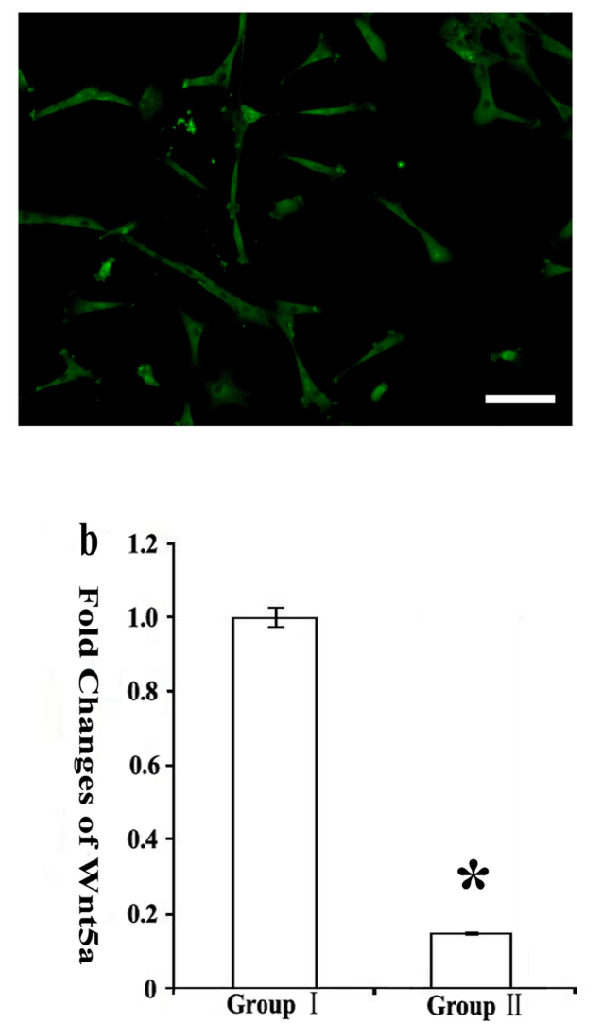

Figure 3. Expression of Wnt5a in hASCs after Wnt5a siRNA knock down. (A) Compared with Group I, the fluorescence intensity of Wnt5a in Group II was significantly reduced (white bar $=100 \mu \mathrm{m}$ ). (B) Wnt5a gene expression (a) and Wnt5a protein expression (b) analyzed by relative quantitative analyses. These results showed that Wnt5a expression was significantly lower in Group II than in Group I $(p<0.05)$. (C) Western blot bands representing the Wnt5a protein in Groups I and II. (*significant differences between this two groups)

\section{Analysis of Wnt- and osteogenesis-associated Protein Expression in Cells under Tensile Stress by Western blots}

In this study, the protein expression of Wnt5a, Wnt10b, RUNX2 and SPP1 was analyzed using western blots. The western blot results are shown in Figure 5. Compared with Group A, the protein levels of Wnt10b were significantly higher in Group B cells $(p<0.05)$, and the protein levels of Wnt5a were significantly lower $(p<0.05)$; however, the protein levels of RUNX2 and SPP1 were not significantly different between Groups A and B ( $p \tilde{\mathrm{A}}$ 0.05). Compared with Groups A and B, the levels of all the protein analyzed were significantly higher in Group $\mathrm{C}(p<0.05)$. Compared with Group C, the protein levels of Wnt5a and RUNX2 were significantly lower in Group D $(p<0.05)$, while Wnt10b and SPP1 protein expression were significantly higher $(p<0.05)$. 

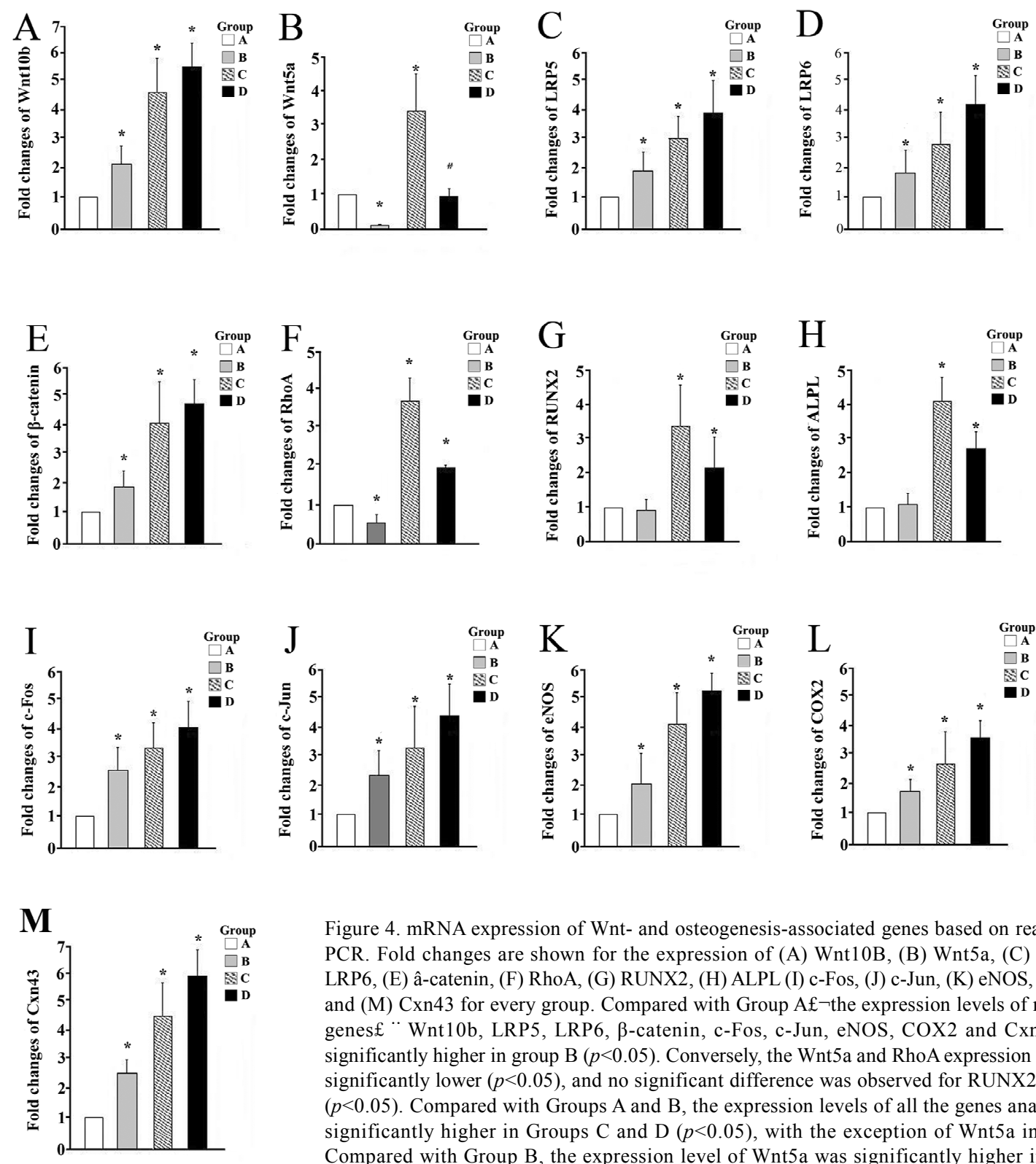

Figure 4. mRNA expression of Wnt- and osteogenesis-associated genes based on real-time RTPCR. Fold changes are shown for the expression of (A) Wnt10B, (B) Wnt5a, (C) LRP5, (D) LRP6, (E) â-catenin, (F) RhoA, (G) RUNX2, (H) ALPL (I) c-Fos, (J) c-Jun, (K) eNOS, (L) COX2, and (M) Cxn43 for every group. Compared with Group $A £ \neg$ the expression levels of most of the genes£ ' Wnt10b, LRP5, LRP6, $\beta$-catenin, c-Fos, c-Jun, eNOS, COX2 and Cxn43£广owere significantly higher in group B $(p<0.05)$. Conversely, the Wnt5a and RhoA expression levels were significantly lower $(p<0.05)$, and no significant difference was observed for RUNX2 and ALPL $(p<0.05)$. Compared with Groups A and B, the expression levels of all the genes analyzed were significantly higher in Groups C and D $(p<0.05)$, with the exception of Wnt5a in Group D. Compared with Group B, the expression level of Wnt5a was significantly higher in Group D $(p<0.05)$. Compared with Group C, the expression levels of Wnt5a, RhoA, RUNX2 and ALPL were significantly lower in Group D $(p<0.05)$, but the expression levels of Wnt10b, LRP5, LRP6, $\beta$-catenin, c-Fos, c-Jun, eNOS, COX2 and Cxn43 were significant higher $(p<0.05)$. Two-way ANOVA test showed the tensile stress $(p<0.05)$, Wnt5a siRNA $(p<0.05)$, combination of tensile stress and Wnt5a siRNA $(\mathrm{p}<0.05)$ affected the genes expression associated with osteogenic differentiation of human adipose-derived stem cells. (* significant difference between this group and the others; \# significant difference between this group and Group B)

Compared with Groups A and B, the expression of all the proteins analyzed was significantly higher in Group D $(p<0.05)$, with the exception of Wnt5a. Two-way ANOVA test showed the tensile stress $(p<0.05)$, Wnt5a siRNA $(p<0.05)$, combination of tensile stress and Wnt5a siRNA $(p<0.05)$ affect the proteins expression associated with osteogenic differentiation of human adiposederived stem cells significantly.

\section{Discussion}

ASCs were selected as the experimental system in this study because of their many obvious advantages mentioned in Introduction. In recent years, cellular biomechanical experiments in vitro have been widely used to simulate the biomechanical environment in vivo ${ }^{38-40)}$. In this study, we chose tensile stress applied by a four-point bending system as the mechanical stimulation because tensile stress is considered an important osteogenesis-promoting factor based on previous studies ${ }^{37}$. The tensile stress value was restricted to $2000 \mu \varepsilon$ to avoid pathological responses in cells caused by supra-physiological loading and because $2000 \mu \varepsilon$ is considered equivalent to in vivo physiological 
A
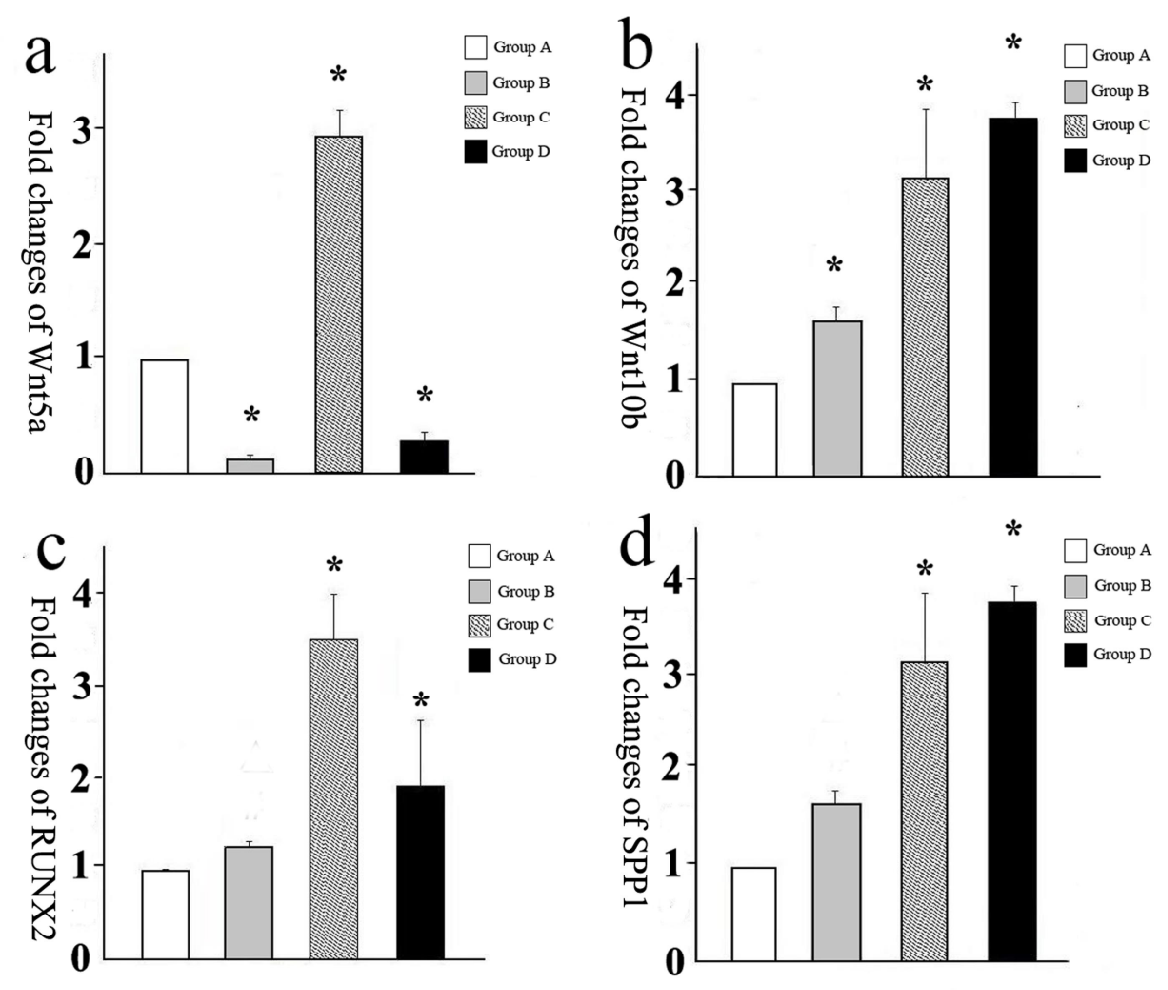

$\mathrm{B}$

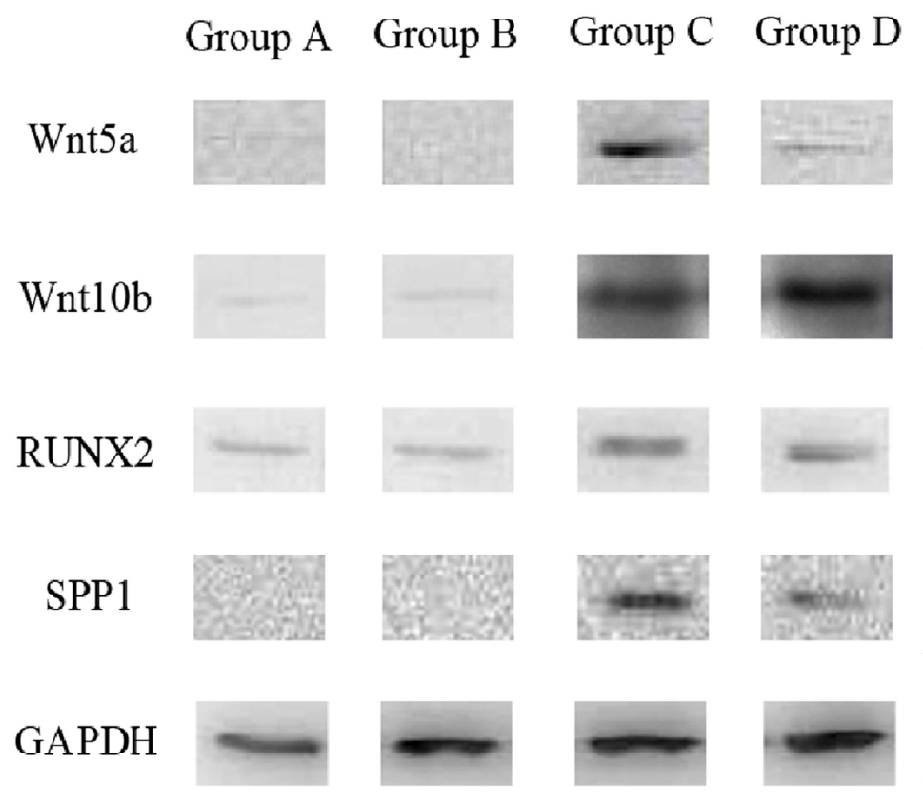

Figure 5. Protein expression of Wnt- and osteogenesis-associated factors in cells under tensile stress detected by Western blot analysis. (A) Compared with Group A, the expression level of Wnt10b was significantly higher in group B $(p<0.05)$, and the expression level of Wnt5a was significantly lower $(p<0.05)$. No significant changes were observed for RUNX2 and SPP1 $(p<0.05)$. Compared with Groups A and B, the expression of all the proteins analyzed was significantly higher in Group C $(p<0.05)$. Compared with Group C, the protein expression levels of Wnt5a and RUNX2 were significantly lower in Group D $(p<0.05)$, but Wnt10b and SPP1 expression were significantly higher $(p<0.05)$. Compared with Groups A and $\mathrm{B}$, the expression of all the proteins analyzed was significantly higher in Group D $(p<0.05)$, with the exception of Wnt5a. (B) Western blot bands representing the Wnt5a, Wnt10b, RUNX2 and SPP1 proteins. Two-way ANOVA test showed the tensile stress ( $<<0.05)$, Wnt5a siRNA $(p<0.05)$, combination of tensile stress and Wnt5a siRNA $(p<0.05)$ affected the proteins expression associated with osteogenic differentiation of human adipose-derived stem cells. (*significant differences between this group and the others) 
Hong-ming Du et al.: Wnt Signaling in the Osteogenic Differentiation of Human Adipose-derived Stem Cells under Mechanical Stimulation loading ${ }^{41,42)}$. Our previous study confirmed that $2000 \mu \varepsilon$ tensile stress can indeed effectively promote the osteogenic differentiation of hASCs ${ }^{37)}$.

RNAi has been widely used in gene silencing studies ${ }^{39)}$. In this study, Wnt5a expression was reduced in hASCs using this technique. The fluorescence intensity of Wnt5a in Group II was significantly lower than that in Group I. The results of real-time RT-PCR and Western blot analysis showed that Wnt5a expression was significantly lower in Group II than in Group I. This result indicates that the RNAi technique successfully reduced Wnt5a expression in hASCs in this experiment.

Cawthorn et al. found that $\mathrm{Wnt} 10 \mathrm{~b}$ is an upstream regulator of PPAR $\gamma$ and CEBP/ $\alpha$ that can inhibit their expression ${ }^{27)}$ and promote osteogenic differentiation of stem cells ${ }^{24,25}$. In our experiment, expression at the mRNA and protein levels was detected using real-time RT-PCR and western blot analysis. Compared with Group A, Wnt10b expression was significantly higher in Group C, non-siRNA-treated hASCs under tensile stress, and the expression levels of the Wnt10b downstream targets LRP5/ 6 and $\beta$-catenin were also significantly higher. The important Wnt/ $\beta$-catenin target genes c-Fos, c-Jun, eNOS, COX2 and Cxn43 all exhibited increased expression in Group $\mathrm{C}$ under tensile stress $^{32,43,44)}$. Thus, tensile stress stimulation activated the Wnt/ $\beta$ catenin pathway. Based on existing evidence, the Wnt/ $\beta$-catenin pathway can directly stimulate RUNX2 expression and thus promote osteogenic differentiation ${ }^{32}$. Furthermore, the SPP1 protein is an important promoter of MSCs maturity during the osteogenic differentiation process ${ }^{45}$. Compared with Group A, RUNX2, ALPL and SPP1 exhibited increased expression in hASCs after tensile stress loading in Group C, suggesting that these cells were in the process of osteogenic differentiation. Therefore, tensile stress stimulation activated the Wnt/ $\beta$-catenin pathway, promoted osteogenic differentiation, and indirectly promoted maturation in hASCs. After tensile stress loading, Wnt5a expression was also significantly higher in the non-siRNA-treated hASCs of Group C than in Group A, hASCs without mechanical stimulation or Group B or D hASCs treated with Wnt5a siRNA. Furthermore, expression of RhoA, a key downstream target, was significantly higher in Group C than in Groups B and D. RhoA can act on the RUNX2 gene directly and increase its expression. RhoA and its related proteins play an important role in promoting the osteogenic and chondrogenic differentiation of $\mathrm{MSCs}^{46}$. Therefore, intermittent tensile stress stimulation not only activates the canonical pathway but also activates the non-canonical Wnt/ $\mathrm{Ca}^{2+}$ pathway, which mainly consists of Wnt5a and RhoA, to promote the osteogenic differentiation of hASCs.

Bolzoni et al. have confirmed that Wnt5a is involved in the osteogenic differentiation process of hASCs under tensile stress ${ }^{30)}$, and we believe that it is an important molecule for development and osteogenic differentiation. Compared with the non-siRNA-

treated hASCs in Group C, the protein levels of Wnt5a, RhoA, RUNX2 and SPP1 were significantly lower in the Wnt5a-siRNAtreated hASCs in Group D. These results showed that the RNAi successfully inactivated the non-canonical $\mathrm{Wnt} / \mathrm{Ca}^{2+}$ pathway, which is mainly composed of Wnt5a and RhoA, and thereby directly inhibited the process of osteogenic differentiation in hASCs. Norvell et al. showed that Wnt5a significantly inhibits the expression of $\beta$-catenin in vitro ${ }^{47)}$. In the present study, $\beta$ catenin expression was higher in the Wnt5a-siRNA-treated hASCs in Group B than in Group A, indicating that the presence of Wnt5a inhibits the effect of $\beta$-catenin in vitro. After tensile stress loading, Wnt5a expression in Group D declined compared with Group C, which means that the RNAi decreased the expression of Wnt5a and enhanced the expression of $\beta$-catenin in vitro. These results indicate that $\mathrm{Wnt} / \mathrm{Ca}^{2+}$ and $\mathrm{Wnt} / \beta$-catenin promote osteogenesis and inhibit with each other in vitro, and the interaction between these two pathways is very complex.

Although Wnt5a expression is lower in the Wnt5a-siRNAtreated hASCs from Group D than in Group A, it is higher in Group D than in Group B. This phenomenon suggests that tensile stress increases the potential for Wnt5a activation and the expression of Wnt5a was not inhibited completely by RNAi during tensile stress.

It is well known that RUNX2 plays an important regulatory role in the osteogenic differentiation of MSCs, ALPL and SPP1 are important maturation-promoting factors during the osteogenic differentiation of MSCs. High expression of these genes can promote the osteogenic differentiation of hASCs and accelerate their maturation. In this study, RUNX2, ALPL and SPP1 expression levels were significantly higher in Group C hASCs under tensile stress than in Group A cells without tensile stress loading; this indicates that tensile stress stimulation can effectively promote osteogenic differentiation in hASCs. The expression levels of RUNX2, ALPL and SPP1 were also significantly higher in Group D than in Group A hASCs without tensile stress loading. This indicates that although the osteogenic stimulatory effect was decreased by Wnt5a siRNA, tensile stress stimulation activated the canonical Wnt signaling pathway and thus significantly promoted osteogenesis.

RUNX2 is considered a target of the Wnt/ $\beta$-catenin pathway ${ }^{32)}$ and RhoA in the $\mathrm{Wnt} / \mathrm{Ca}^{2+}$ pathway ${ }^{30)}$, and RUNX2 expression should be activated by elevated expression of the Wnt/ $\beta$-catenin and $\mathrm{Wnt} / \mathrm{Ca}^{2+}$ pathways. In this study, although Wnt5a was knocked down in group B, RUNX2 expression was the same in Groups A and $\mathrm{B}$, suggesting that the osteogenic differentiation of hASCs was not affected by Wnt5a knock down. However, as we know, if the $\mathrm{Wnt} / \mathrm{Ca}^{2+}$ pathway was blocked, the osteogenic response of the cells should also be inhibited. Therefore, the RUNX2 result in this study was interesting. One possible explanation for this result may be that Wnt5a siRNA increased the expression of 
J.Hard Tissue Biology Vol. 24(2):169 -180, 2015

Wnt10b and its downstream targets in Group B; thus, Wnt10b promoted the expression of RUNX2 to counteract RUNX2 downregulation caused by Wnt5a knock down. Finally, the expression level of RUNX2 was not obviously affected by the interaction between the two pathways. Expression of RUNX2 in Groups C and D correlated with the expression levels of Wnt5a and Wnt10b, suggesting that tensile stress activated the Wnt/ $\beta$-catenin and Wnt/ $\mathrm{Ca}^{2+}$ pathways at the same time.

In summary, our study further confirmed that intermittent tensile stress can promote the maturation and osteogenic differentiation of hASCs and can also activate the $\mathrm{Wnt} / \beta$-catenin pathway and a non-canonical Wnt pathway that is made up of Wnt5a and RhoA in hASCs. This non-canonical Wnt pathway may have the potential to inhibit the Wnt/ $\beta$-catenin pathway, which is activated by Wnt10b. Wnt5a knock down seemed to increase expression of the Wnt/ $\beta$-catenin pathway, which is activated by Wnt10b.

\section{Acknowledgements}

This work was supported by research grants from the National Natural Science Foundation of China (No.10502037 and 31070833) and the Science and Technology Foundation of Sichuan Province (No.2010GZ0225, 2011GZ0335 and 2009SZ0139), which are gratefully acknowledged. All experimental works were completed in the State Key Laboratory of Oral Diseases, China.

\section{References}

1. Weyts FA, Bosmans B, Niesing R, van Leeuwen JP and Weinans H. Mechanical control of human osteoblast apoptosis and proliferation in relation to differentiation. Calcif Tissue Int 72: 505-512, 2003

2. Brighton CT, Strafford B, Gross SB, Leatherwood DF, Williams JL and Pollack SR. The proliferative and synthetic response of isolated calvarial bone cells of rats to cyclic biaxial mechanical strain. J Bone Joint Surg Am 73: 320 331,1991

3. Li YJ, Batra NN, You L, Meier SC, Coe IA, Yellowley CE and Jacobs CR. Oscillatory fluid flow affects human marrow stromal cell proliferation and differentiation. J Orthop Res 22: 1283-1289, 2003

4. Sahoo S, Ouyang H, Goh JC, Tay TE and Toh SL. Characterization of a novel polymeric scaffold for potential application in tendon/ligament tissue engineering. Tissue Eng 12: 91-99, 2006

5. Kafienah W, Mistry S, Dickinson SC, Sims TJ, Learmonth I and Hollander AP. Three-dimensional cartilage tissue engineering using adult stem cells from osteoarthritis patients. Arthritis Rheum 56: 177-187, 2007

6. Derubeis AR and Cancedda R. Bone marrow stromal cells (BMSCs) in bone engineering: limitations and recent advances. Ann Biomed Eng 32: 160-165, 2004

7. Koike M, Shimokawa H, Kanno Z, Ohya K and Soma K. Effects of mechanical strain on proliferation and differentiation of bone marrow stromal cell line ST2. J Bone Miner Metab 23: 219-225, 2005

8. Park JS, Chu JS, Cheng C, Chen F, Chen D and Li S. Differential effects of equiaxial and uniaxial strain on mesenchymal stem cells. Biotechnol Bioeng 88: 359-368, 2004

9. Sumanasinghe RD, Bernacki SH and Loboa EG. Osteogenic differentiation of human mesenchymal stem cells in collagen matrices: effect of uniaxial cyclic tensile strain on bone morphogenetic protein (BMP-2) mRNA expression. Tissue Eng 12: 3459-3465, 2006

10. De Ugarte DA, Morizono K, Elbarbary A, Alfonso Z, Zuk PA, Zhu M, Dragoo JL, Ashjian P, Thomas B, Benhaim P, Chen I, Fraser J and Hedrick MH. Comparison of multilineage cells from human adipose tissue and bone marrow. Cell Tissue Organ 174: 101-109, 2003

11. Kakudo N, Shimotsuma A, Miyake S, Kushida S and Kusumoto K. Bone tissue engineering using human adiposederived stem cells and honeycomb collagen scaffold. J Biomed Mater Res A 84: 191-197, 2008

12. Lin Y, Wang T, Wu L, Jing W, Chen X, Li Z, Liu L, Tang W, Zheng $\mathrm{X}$ and Tian W. Ectopic and in situ bone formation of adipose tissue-derived stromal cells in biphasic calcium phosphate nano composite. J Biomed Mater Res A 81: 900910, 2007

13. Wu L, Wu Y, Lin Y, Jing W, Nie X, Qiao J, Liu L, Tang W and Tian W. Osteogenic differentiation of adipose derived stem cells promoted by overexpression of osterix. Mol Cell Biochem 301: 83-92, 2007

14. Yu HC, Wu TC, Chen MR, Liu SW, Chen JH and Lin KM. Mechanical stretching induces osteoprotegerin in differentiating $\mathrm{C} 2 \mathrm{C} 12$ precursor cells through noncanonical Wnt pathways. J Bone Miner Res 25: 1128-1137, 2010

15. Yu B, Yu D, Cao L, Zhao X, Long T, Liu G, Tang T and Zhu Z. Simulated microgravity using a rotary cell culture system promotes chondrogenesis of human adipose-derived mesenchymal stem cells via the p38 MAPK pathway. Biochem Biophys Res Commun 414: 412-418, 2011

16. Kahler RA and Westendorf JJ. Lymphoid enhancer factor-1 and beta-catenin inhibit Runx2-dependent transcriptional activation of the osteocalcin promoter. J Biol Chem 278: 11937-11944, 2003

17. Kahler RA, Galindo M, Lian J, Stein GS, van Wijnen AJ and Westendorf JJ. Lymphocyte enhancer-bindingfactor 1 (Lef1) inhibits terminal differentiation of osteoblasts. J Cell Biochem 97: 969-983, 2006.

18. Eijken M, Meijer IM, Westbroek I, Koedam M, Chiba H, 
Hong-ming Du et al.: Wnt Signaling in the Osteogenic Differentiation of Human Adipose-derived Stem Cells under Mechanical Stimulation

Uitterlinden AG, Pols HA and van Leeuwen JP. Wnt signaling acts and is regulated in a human osteoblast differentiation dependent manner. J Cell Biochem 104: 568-579, 2008

19. Kahler RA, Yingst SM, Hoeppner LH, Jensen ED, Krawczak $\mathrm{D}$, Oxford JT and Westendorf JJ. Collagen 11a1 is indirectly activated by lymphocyte enhancer-binding factor 1 (Lef1) and negatively regulates osteoblast maturation. Matrix Biol 27: 330-338, 2008

20. Ikeda S, Kishida S, Yamamoto H, Murai H, Koyama S and Kikuchi A. Axin, a negative regulator of the Wnt signaling pathway, forms a complex with GSK-3beta and beta-catenin and promotes GSK-3beta-dependent phosphorylation of beta-catenin. EMBO J 17: 1371-1384, 1998

21. Liu C, Li Y, Semenov M, Han C, Baeg GH, Tan Y, Zhang Z, Lin $\mathrm{X}$ and $\mathrm{He} \mathrm{X}$. Control of beta-catenin phosphorylation/ degradation by a dual-kinase mechanism. Cell 108: 837-847, 2002

22. Ishitani $\mathrm{T}$, Ninomiya-Tsuji $\mathrm{J}$ and Matsumoto K. Regulation of lymphoid enhancer factor 1/T-cell factor by mitogenactivated protein kinase-related Nemo-like kinase-dependent phosphorylation in Wnt/beta-catenin signaling. Mol Cell Biol 23: 1379-1389, 2003

23. Barker $\mathrm{N}$ and Catenins $\mathrm{CH}$. Wnt signaling and cancer. Bioessays 22: 961-965, 2000

24. Bennett CN, Longo KA, Wright WS, Suva LJ, Lane TF, Hankenson KD and MacDougald OA. Regulation of osteoblastogenesis and bone mass by Wnt10b. Proc Natl Acad Sci USA 102: 324-3329, 2005

25. Bennett CN, Ouyang H, Ma YL, Zeng Q, Gerin I, Sousa KM, Lane TF, Krishnan V, Hankenson KD and MacDougald $\mathrm{OA}$. Wnt10b increases postnatal bone formation by enhancing osteoblast differentiation. J Bone Miner Res 22: 1924-1932, 2007

26. Zmuda JM, Yerges LM, Kammerer CM, Cauley JA, Wang $\mathrm{X}$, Nestlerode CS, Wheeler VW, Patrick AL, Bunker CH, Moffett SP and Ferrell RE. Association analysis of WNT10B with bone mass and structure among individuals of African ancestry. J Bone Miner Res 24: 437-447, 2009

27 . Cawthorn WP, Bree AJ, Yao Y, Du B, Hemati N, MartinezSantibañez G and MacDougald OA. Wnt6, Wnt10a and Wnt 10 b inhibit adipogenesis and stimulate osteoblastogenesis through a $\beta$-catenin-dependent mechanism. Bone 50: 477-489, 2012

28. Takada I, Mihara M, Suzawa M, Ohtake F, Kobayashi S, Igarashi M, Youn MY, Takeyama K, Nakamura T, Mezaki Y, Takezawa S, Yogiashi Y, Kitagawa H, Yamada G, Takada S, Minami Y, Shibuya H, Matsumoto K and Kato S. A histone lysine methyltransferase activated by non-canonical Wnt signalling suppresses PPAR-gamma transactivation. Nat Cell Biol, 9: 1273-1285, 2007.
29. Fukuda T and Takeda S. Regulation of osteoblastic differentiation by Wnt signals.Clin Calcium 23: 825-830, 2013

30. Bolzoni M, Donofrio G, Storti P, Guasco D, Toscani D, Lazzaretti M, Bonomini S, Agnelli L, Capocefalo A, Dalla Palma B, Neri A, Nicolini F, Lisignoli G, Russo F, Colla S, Aversa $\mathrm{F}$ and Giuliani N. Myeloma cells inhibit noncanonical wnt co-receptor ror2 expression in human bone marrow osteoprogenitor cells: effect of wnt5a/ror2 pathway activation on the osteogenic differentiation impairment induced by myeloma cells. Leukemia 27: 451-463, 2013

31. Yamashita T, Takahashi N and Udagawa N. New roles of osteoblasts involved in osteoclast differentiation. World J Orthop 3; 175-181, 2012

32. Gaur T, Lengner CJ, Hovhannisyan H, Bhat RA, Bodine PV, Komm BS, Javed A, van Wijnen AJ, Stein JL, Stein GS and Lian JB. Canonical WNT signaling promotes osteogenesis by directly stimulating Runx 2 gene expression. Biol Chem 280: 33132-33140, 2005

33. Kobayashi Y. Roles of Wnt signaling in bone metabolism. Clin Calcium 22: 1701-1706, 2012

34. Marcellini S, Henriquez JP and Bertin A. Control of osteogenesis by the canonical Wnt and BMP pathways in vivo: cooperation and antagonism between the canonical Wnt and BMP pathways as cells differentiate from osteochondroprogenitors to osteoblasts and osteocytes. Bioessays 34: 953-962, 2012

35. Galli C, Passeri G and Macaluso GM. Osteocytes and WNT: The mechanical control of bone formation. J Dent Res 89 331-343, 2010

36. Lin Y, Liu L, Li Z, Qiao J, Wu L, Tang W, Zheng X, Chen $X$, Yan Z and Tian W. Pluripotency potential of human adipose-derived stem cells marked with exogenous green fluorescent protein. Mol Cell Biochem 291: 1-10, 2006

37. Du HM, Zheng XH, Wang LY, Tang W, Liu L, Jing W, Lin YF, Tian WD and Long J. The osteogenic response of undifferentiated human adipose-derived stem cells under mechanical stimulation. Cell Tissue Organ 196: 313-324, 2012

38. Katanosaka Y, Bao JH, Komatsu T, Suemori T, Yamada A, Mohri S and Naruse K. Analysis of cyclic-stretching responses using cell-adhesion-patterned cells. J Biotechnol 133: 82-89, 2008

39. Al-Salleeh F, Beatty MW, Reinhardt RA, Petro TM and Crouch L. Human osteogenic protein-1 induces osteogenic differentiation of adipose-derived stem cells harvested from mice. Arch Oral Biol 53: 928-936, 2008

40. Wang JH, Yang G and Li Z. Controlling cell responses to cyclic mechanical stretching. Ann Biomed Eng 33: 337-342, 2005 
J.Hard Tissue Biology Vol. 24(2):169 -180, 2015

41. Martin I, Wendt D and Hebere M. The role of bioreactors in tissue engineering. Trends Biotechnol 22: 80-86, 2004

42. Butler DL, Goldstein SA and Guilak F. Functional tissue engineering: the role of biomechanics. J Biomech Eng 122: 570-575, 2000

43. Ramachandran PV and Ignacimuthu S. RNA interferencea silent but an efficient therapeutic tool. Appl Biochem Biotechnol 169: 1774-1789, 2013

44. Robinson JA, Chatterjee-Kishore M, Yaworsky PJ, Cullen DM, Zhao W, Li C, Kharode Y, Sauter L, Babij P, Brown EL, Hill AA, Akhter MP, Johnson ML, Recker RR, Komm BS and Bex FJ. Wnt/beta-catenin signaling is a normal physiological response to mechanical loading in bone. J Biol
Chem 281: 31720-31728, 2006

45. Malaval L, Wade-Guéye NM, Boudiffa M, Fei J, Zirngibl R, Chen F, Laroche N, Roux JP, Burt-Pichat B, Duboeuf F, Boivin G, Jurdic P, Lafage-Proust MH, Amédée J, Vico L, Rossant $\mathrm{J}$ and Aubin JE. Bone sialoprotein plays a functional role in bone formation and osteoclastogenesis. J Exp Med 205: 1145-1153, 2008

46. Arnsdorf EJ, Kwon RY and Jacobs CR. Mechanically induced osteogenic differentiation - the role of RhoA, ROCKII and cytoskeletal dynamics. J Cell Sci 122: 546-553, 2009

47. Norvell SM, Alvarez M, Bidwell JP and Pavalko FM. Fluid shear stress induces beta-catenin signaling in osteoblasts. Calcif Tissue Int 75: 396-404, 2004 